\title{
Hemorrhagic pulmonary contusion secondary to blunt force trauma in a professional hockey player
}

\author{
Christopher M Ziebell and Larry Kravitz* \\ Department of Emergency Medicine, University Medical Center Brackenridge, SETON Event Medicine Institute, and Dell Medical School at the University of Texas, \\ Austin, Texas, USA
}

\begin{abstract}
Introduction: Pulmonary contusions are relatively common in patients with high injury blunt trauma, and would often predict a complex clinical course. Case reports of pulmonary contusion in elite athletes are very rare. The few reports that do exist in this population suggest a less complex and more benign course for these individuals. This is the first case report of pulmonary contusion in a hockey player.
\end{abstract}

Case Presentation: A 25-year-old Caucasian male was struck in the left chest by a hockey puck delivered at high speed as an opposing player was shooting at the goal from the blue line. He immediately experienced hemoptysis. Chest X-Ray suggested, and CT scanning confirmed the presence of a pulmonary contusion. The player recovered swiftly, returned to practice within 2 days, and played in the next game successfully.

Conclusion: Immediate hemoptysis after blunt impact to the chest should indicate a search for pulmonary contusion. While no specific guidelines currently exist for managing elite athletes with pulmonary contusion, it appears that return to athletics should be guided by clinical status and allowed as the athlete feels capable.

\section{Introduction}

Ice hockey is an aggressive contact sport. Injuries resulting from the sport have been cataloged extensively [1-11]. Although a variety of injuries have been described, chest injuries are surprisingly rare, and pulmonary contusion has not been reported to date [12-14]. In athletics overall, there have been four previous case reports of pulmonary contusion in athletes. Of these, three involved football players, and one involved a competitive diver. As there are no pathognomonic signs or symptoms of pulmonary contusion, the diagnosis may be easily missed. Immediate hemoptysis following trauma has been rarely documented as an indicator of pulmonary contusion, though this symptom was present in all case reports to date involving elite athletes. We describe the first case of a hockey player who suffered immediate hemoptysis associated with a pulmonary contusion after impact by a hockey puck. Hockey pucks are composed of galavanized rubber and are frozen to a temperature between $14 \mathrm{~F}$ and $20 \mathrm{~F}$ for competitive play. Slap shots in hockey are known to travel at 80-100 mph. factor, and (5) I do not consider this at all. Results were converted to numerical scores from $1-5$, with 5 being the best rating (reverse order of aforementioned list.) A mean and standard deviation were calculated using Microsoft Excel.

\section{Case Presentation}

A 25 year old professional hockey player defenseman was engaged with a player from the opposing team who was attempting to take a shot at the goal from the blue line. The opponent fired a slap shot toward the goal, and the athlete was struck by the puck in the left lateral chest wall. Immediately after impact, the player experienced localized chest pain and hemoptysis. He experienced mild shortness of breath. In the first 10 minutes after impact, he had approximately 8 coughing episodes, each of which produced 3-5 $\mathrm{ml}$ of frank blood. Coughing and hemoptysis were relieved by sitting forward, and aggravated by sitting upright or laying back. The player was maintained in position of comfort and transported to a level 4 trauma center minutes from the arena.

On arrival to the hospital, his BP was 135/74, HR 77, RR 20, and Pulse Ox was $94 \%$. His pain score was 9 of 10 . His physical examination was remarkable for an abrasion along the left anterior chest wall. There was no deformity, crepitance, or instability. The area was tender, but visual contusion had not yet developed. Breath sounds were full and equal bilaterally. A portable chest x-ray revealed mild groundglass opacity of the left lung base with obscuration of the lateral left hemidiaphragm (Figure 1).

As a follow up to this x-ray, a CT was performed (Figure 2), which confirmed the presence of the pulmonary contusion.

Although his hemoptysis resolved while at this hospital, it was felt that the athlete would require a higher level of care due to this injury, and he was transferred to a level 2 trauma center a few miles away. During this Emergency Department visit, the patient did not require any medications and was never in receipt of supplemental oxygen.

On arrival at the level 2 trauma center, his pain was down to a $5 / 10$. His oxygen saturation was $97 \%$. He had experienced no further hemoptysis. He was placed in observation overnight, during which time he slept comfortably and required no pain medications and no supplemental oxygen. He was discharged early the next morning.

*Correspondence to: Larry Kravitz, MD, University Medical Center Brackenridge, SETON Event Medicine Institute, and Dell Medical School at the University of Texas, Austin, Texas, USA, Tel: 512-338-8838; E-mail: 1kravitz.md@gmail.com

Received: October 17, 2018; Accepted: October 27, 2018; Published: October 31,2018 


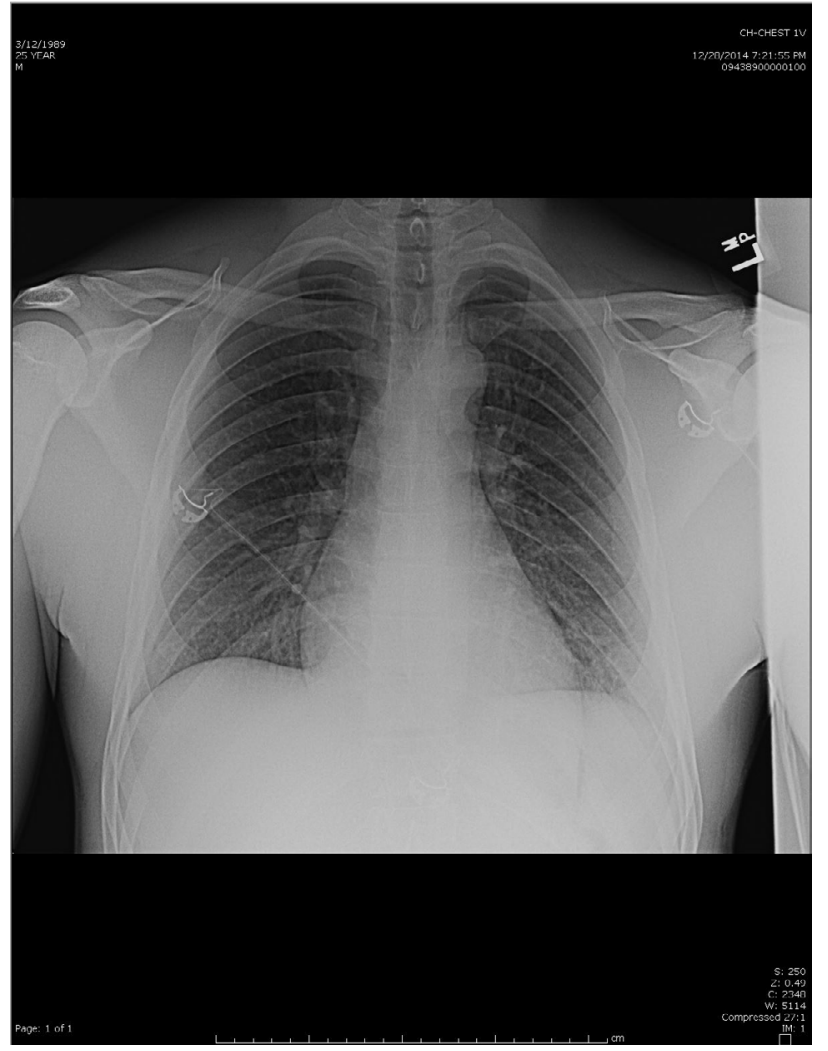

Figure 1. A portable chest x-ray revealed mild ground-glass opacity of the left lung base with obscuration of the lateral left hemidiaphragm

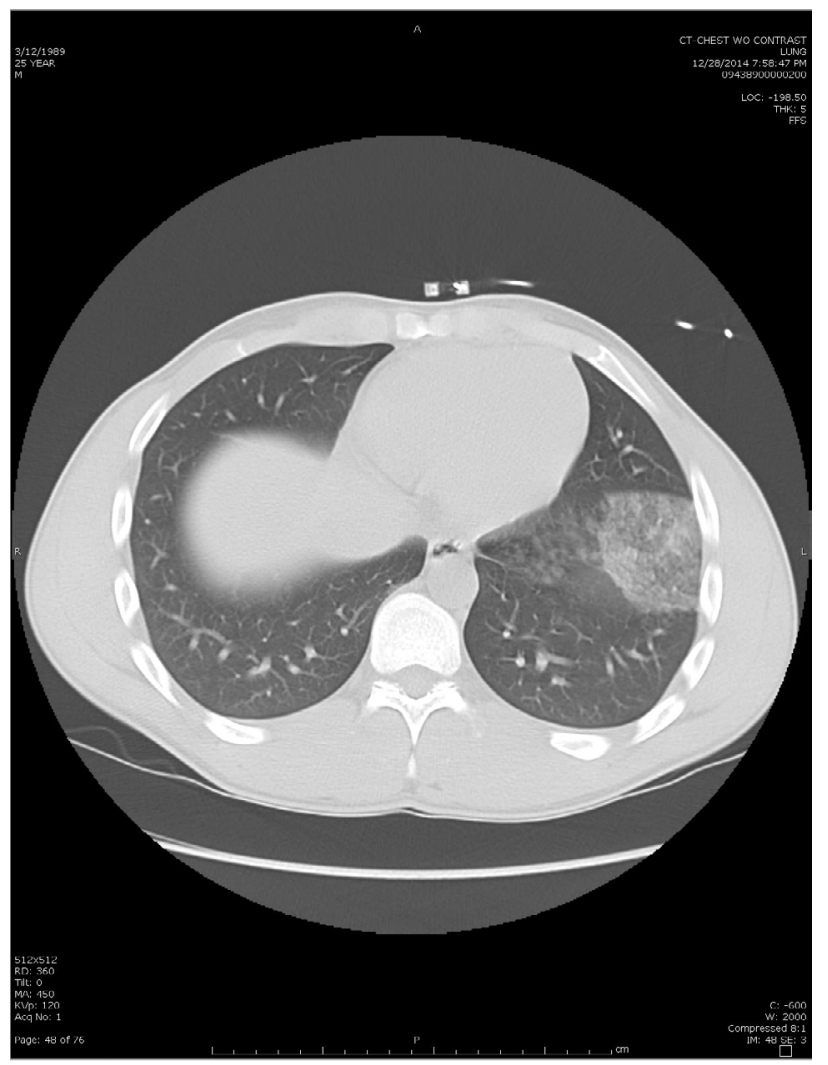

Figure 2. As a follow up to this $\mathrm{x}$-ray, a CT was performed, which confirmed the presence of the pulmonary contusion

\section{Discussion}

Pulmonary contusion is the most common lung injury resulting from blunt trauma [15], though it has rarely been reported in athletes. Only four case reports of pulmonary contusion in athletes have been described. Three of these were in football players, and the fourth was in a competitive diver. Due to the rarity of this condition in athletes, there exist no guidelines to assist the team clinician in making decisions regarding need for hospitalization, duration of hospitalization, or return to practice or competition.

The condition is characterized by parenchymal hemorrhage with interstitial edema and alveolar collapse, all of which could potentially lead to compromised respiratory function [16].

Although the examination of this patient revealed clear breath sounds, findings of crackles, rales or diminished breath sounds do occur in patients with pulmonary contusion. The clinical manifestations in this case, tachypnea, chest pain, dyspnea, and hemoptysis are all consistent with typical presentations of this condition.

Prognosis in pulmonary contusion appears to correlate most closely with findings on initial chest $\mathrm{x}$-ray. A normal initial chest $\mathrm{x}$-ray suggests a benign course, $[17,18]$ and may not require subsequent CT scanning. The size of the abnormality on initial chest $\mathrm{x}$-ray correlates with the clinical course, but the size on CT does not. In this case, the presence of abnormality on the chest $\mathrm{x}$-ray was an appropriate indication for CT scanning and subsequent hospitalization.

Treatment is entirely supportive. Controlling pain, incentive spirometry, and respiratory treatments are all reasonable in the care of these patients. To reduce the risk of deterioration, one author recommends limiting fluid intake in an effort to limit the development of pulmonary edema [19], but this has not borne out in subsequent literature [20]. Complications such as pneumonia and ARDS are commonly described in pulmonary contusion from high velocity impact such as MVA, and may require mechanical ventilatory support $[21,22]$. In the absence of such complications, the effects of pulmonary contusion typically resolve in 3-5 days with only supportive care. Prophylactic antibiotics and steroids [23] do not appear to offer benefit in pulmonary contusion [24].

\section{Conclusions}

Because there are so few case reports of pulmonary contusion in athletes, and because this is the first case report specifically in a hockey player, precise guidelines for the management of these cases do not exist. However, commonalities among all five athletes who are described to have pulmonary contusion suggest that progressive return to athletics can be allowed as tolerated once symptoms have resolved.

\section{References}

1. Kazuhara K, Shimamoto H, Mase Y (2009) Ice Hockey Injuries in a Japanese Elite Team: A 3-Year Prospective Study. J Athl Train 44: 208-214.

2. Tuominen M, Stuart MJ, Aubry M, Kannus P, Parkkari J (2015) Injuries in men's international ice hockey: a 7-year study of the International Ice Hockey Federation Adult World Championship Tournaments and Olympic Winter Games. Br J Sports Med 49: 30-36.

3. Pettersson M, Lorentzon R (1993) Ice hockey injuries: a 4-year prospective study of a Swedish élite ice hockey team. Br J Sports Med 27: 251-254. [Crossref]

4. Jørgensen U, Schmidt-Olsen S (1986) The epidemiology of ice hockey injuries. $\mathrm{Br} J$ Sports Med 20: 7-9. [Crossref]

5. Mölsä J, Airaksinen O, Näsman O, Torstila I (1997) Ice Hockey Injuries in Finland. A Prospective Epidemiologic Study. Am J Sports Med 25: 495-499. 
6. Mölsä J, Kujala U, Näsman O, Lehtipuu TP, Airaksinen O (2000) Injury profile in ice hockey from the 1970s through the 1990s in Finland. Am J Sports Med 28: 322-327. [Crossref]

7. Moslener MD, Wadsworth LT (2010) Ice hockey: a team physician's perspective. Curr Sports Med Rep 9: 134-138. [Crossref]

8. Deits J, Yard EE, Collins CL (2010) Patients with Ice Hockey Injuries Presenting to US Emergency Departments, 1990-2006. J Athl Train 45: 467-474.

9. McKnight CM, Ferrara MS, Czerwinska JM (1992) Intercollegiate ice hockey injuries: a three-year analysis. $J$ Athl Train 27: 338-343. [Crossref]

10. Lorentzon R, Wedren H, Pietila T (1988) Incidence, Nature, and Causes of Ice Hockey Injuries. A Three-Year Prospective Study of a Swedish Elite Ice Hockey Team. Am J Sports Med 16: 392-396.

11. Daly PJ, Sim FH, Simonet WT (1990) Ice hockey injuries. A review. Sports Med 10: 122-131. [Crossref]

12. Meese MA, Sebastianelli WJ: Pulmonary Contusion Secondary to Blunt Trauma in a Collegiate Football Player. Clinical Journal of Sports Medicine 7: 309-310.

13. Lively MW, Stone D (2006) Pulmonary contusion in football players. Clin J Sport Med 16: 177-178. [Crossref]

14. Lively MW (2011) Pulmonary contusion in a collegiate diver: a case report. $J$ Med Case Rep 5: 362. [Crossref]
15. Miller PR, Croce MA, Bee TK (2001) ARDS after Pulmonary Contusion: Accurate Measurement of Contusion Volume Identifies High-Risk Patients. J Trauma 51: 223-230

16. Cohn SM (1997) Pulmonary contusion: review of the clinical entity. $J$ Trauma 42: 973-979. [Crossref]

17. Brathwaite CE, Rodriguez A, Turney SZ, Dunham CM, Cowley R (1990) Blun traumatic cardiac rupture. A 5-year experience. Ann Surg 212: 701-704. [Crossref]

18. Smejkal R, O'Malley KF, David E (1991) Routine Initial Computed Tomography of the Chest in Blunt Torso Trauma. Chest 100: 667-669.

19. Amaral JF (1997) Thoracoabdominal injuries in the athlete. Clin Sports Med 16: 739753. [Crossref]

20. Wanek S, Mayberry JC (2004) Blunt Thoracic Trauma: Flail Chest, Pulmonary Contusion, and Blast Injury. Crit Care Clin 20: 71-81.

21. Cohn SM (1997) Pulmonary contusion: review of the clinical entity. $J$ Trauma 42 973-979. [Crossref]

22. Allen GS, Coates NE (1996) Pulmonary contusion: a collective review. Am Surg 62 895-900. [Crossref]

23. Schuck JM, Snow NJ (1988) Injury to the Chest Wall. In: Mattox KL, Moore EE, Feliciano DV (edn) Trauma, Norwalk: Appleton \& Lange, pp: 321-334.

24. Cohn SM, Dubose JJ (2010) Pulmonary contusion: an update on recent advances in clinical management. World J Surg 34: 1959-1970. [Crossref]

Copyright: $\mathbb{C} 2018$ Ziebell CM. This is an open-access article distributed under the terms of the Creative Commons Attribution License, which permits unrestricted use, distribution, and reproduction in any medium, provided the original author and source are credited. 